\title{
Um estudo sobre exclusão social e depressão a partir do plantão psicológico
}

\section{A study on social exclusion and depression from the psychological emergency attendance}

\section{Un estudio sobre exclusión social y depresión basado en la guardia psicológica}

Mikelly Neves Silva

e-mail: mikellyneves@hotmail.com

Universidade Federal de Jataí

iD (9) Érico Douglas Vieira

e-mail: ericopsi@yahoo.com.br

Universidade Federal de Jataí

Resumo: A partir de intervenções na modalidade de Plantão Psicológico com usuários de uma casa de apoio, buscou-se investigar a exclusão social como possível condição produtora de vivências relativas à depressão. A Teoria Fundamentada, metodologia de natureza qualitativa, foi adotada. Foram selecionados diários de campo produzidos pela equipe de extensão e pesquisaa partir de cada atendimento realizado.Como resultado da investigação destes registros, foram mapeadas vivências depressivas associadas a rupturas relacionais que desvitalizam e geram uma sensação de desenraizamento e não pertencimento. Os maus encontros de su- 
jeitos excluídos com pessoas de outras classes através de olhares de rebaixamento podem aumentar a sensação de vulnerabilidade. Notou-se também que a falta de perspectivas parece provocar uma significativa desvinculação com o mundo. A escuta clínica representou um espaço de emergência das potências dos sujeitos excluídos, além de uma importante fonte de suporte social. Palavras-chave: Exclusão social. Depressão. Plantão Psicológico.

Abstract: Based on interventions with psychological emergency attendance with users of a support institution, we sought to investigate social exclusion as a possible condition that produces experiences related to depression. The Grounded Theory, a qualitative methodology, was adopted. Field diaries produced by the extension and research team were selected from each psychological intervention. As a result of the investigation of these records, were

2

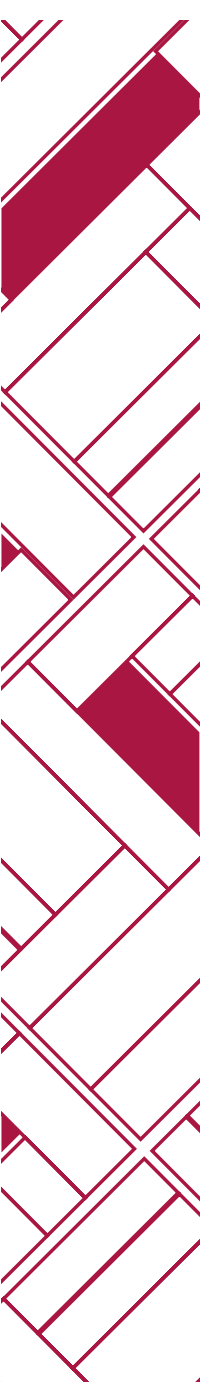
maped depressive experiences associated with relational ruptures that devitalize and generate a feeling of non-belonging. The bad encounters of excluded subjects with people of other classes through discrminatory looks can increase the feeling of vulnerability. It was also noted that the lack of perspectives seems to cause a significant disconnection with the world. Clinical listening represented na space for the appearance of strenght of the excluded subjects, in addition to being an importante source of social support.

Key words: Social exclusion. Depression. Psychologicalemergencyattendance.

Resumen: A partir de intervenciones com Guadia Psicológica com usuarios de uma instituciónde apoyo, se buscó investigar laexclusión social como una posiblecondición que produceexperiencias relacionadas com ladepresión. Teoría Fundamentada em los dados, una metodologia cualitativa, fue elegida como método. De cadain- 
tervención clínica realizada se seleccionarondiarios de campo elaborados por el equipo de extensión e investigación. Como resultado de lainvestigación de estos registros se mapearon experiências depressivas asociadas a rupturas relacionales que desvitalizan y generan um sentimiento de no pertenencia. Los malos encuentros de sujetos excluídos con personas de otrasclases a través de miradas discriminatórias pueden incrementar elsentimiento de vulnerabilidad. La falta de perspectivas parece provocar una desconexión significativa com el mundo. La escucha clínica represento um espacio de emergencia de capacidades de lossujetosexcluidos, además de ser una importante fuente de apoyo social. Palabras clave: Exclusión social. Depresión. Guardia Psicológica.

Data de submissão: $13 / 11 / 2020$ 
Um estudo sobre exclusão social e depressão a partir do plantão psicológico Mikelly Neves Silva • Érico Douglas Vieira

\section{Introdução}

A clínica psicológica com sujeitos excluídos demanda uma expansão em relação às teorias e práticas da Psicologia Clínica tradicional. A ideia de subjetividade universal presente na literatura especializada, revela-se insuficiente para a compreensão dos sofrimentos subjetivos que expressam desigualdades sociais. No Brasil, temos uma naturalização significativa da desigualdade social que produz uma invisibilidade sobre o injusto acesso aos bens materiais e simbólicos, além da existência de uma valoração das pessoas a depender da sua classe social (SOUZA, 2017). Ou seja, há uma construção social e histórica que organiza uma hierarquia na qual determinados grupos sociais são vistos como subumanos, como coisa, em contraposição com as classes incluídas que são vistas como pessoas dignas (SOUZA, 2017; SAFATLE, 2020).

A partir de práticas clínicas psicológicas realizadas com sujeitos excluídos, este artigo tem como objetivo a análise da exclusão social e dos processos de marginalização como condições produtoras de diversas vulnerabilidades. Mais especificamente, o objetivo foi buscar a análise das vivências de depressão como expressões e consequências do lugar social ocupado por pessoas excluídas, que possuem escasso acesso a mecanismos sociais protetores e que são vistas com desprezo pelas classes incluídas (SOUZA, 2015). Estas pessoas vivenciam subjetivamente o descompromisso social e estatal com as suas privações, num processo de culpabilização dos próprios sujeitos de sua condição.De forma tradicional, a depressão geralmente é entendida como uma condição psicopatológica de âmbito individual.

O presente estudo integra o projeto de extensão "Intervenções clínicas institucionais com grupos vulneráveis" e o projeto de pesquisa "Possibilidades de intervenções clínicas com grupos 
Um estudo sobre exclusão social e depressão a partir do plantão psicológico Mikelly Neves Silva • Érico Douglas Vieira

marginalizados a partir do plantão psicológico fundamentado no Psicodrama", ambos executados por uma equipe de discentes e um docente coordenador pertencentes ao curso de Psicologia da Universidade Federal de Jataí - UFJ.Os fundamentos empíricos do trabalho se constituem a partir das intervenções realizadas numa instituição de apoio. Trata-se de um estabelecimento filantrópico que presta cuidados como alimentação (café da manhã e almoço), local para higienização pessoal e estrutura para higienização de roupas, fornecimento de roupas e sapatos e realização de palestras educativas. O público-alvo é constituído por pessoas em situação de rua, andarilhos, "trecheiros" (pessoas que percorrem trechos, de cidade em cidade), desempregados, e trabalhadores de baixa renda, como garis. A equipe de extensão/pesquisa oferta atendimentos psicológicos do tipo Plantão Psicológico, oferecendo um acolhimento pontual para sujeitos excluídos.

A partir do enfoque fenomenológico-existencial, a depressão é concebida como um estado ou uma forma vivencial específica (ROMERO, 1994). Essa concepção se diferencia e transcende a abordagem médica tradicional em que a depressão é uma psicopatologia definida de maneira objetiva com base em classificações pautadas em sintomas detectáveis e causas essencialmente amparadas em fatores orgânicos.Segundo Romero (1994, p. 202), trata-se de "um modo de ser-no-mundo", em que as possibilidades existenciais se fecham com a perda de algo que representava uma base de sustentação para a vida do sujeito. Esse estado pode ser caracterizado por algumas vivências dominantes, tais como: baixa autoestima, autoconfiança reduzida, sentimento prolongado de fracasso pessoal, incapacidade para sair de situações conflitantes, sentimento de perda ou privação de um bem, desmotivação generalizada,queda da vitalidade,isolamento social, culpa, tristeza e sensação de vazio (ROMERO, 1994). 
Um estudo sobre exclusão social e depressão a partir do plantão psicológico Mikelly Neves Silva • Érico Douglas Vieira

De acordo com os dados da Organização Mundial da Saúde $(\mathrm{OMS})^{1}$ sobre depressão, em 2018, no âmbito mundial, mais de 300 milhões de pessoas sofriam com essa condição, sendo este um transtorno em ascensão e a principal causa de incapacidade no mundo. A OMS pontua que além dos fatores psicológicos e biológicos, os fatores sociais contribuem significativamente para a instalação da depressão.As vivências de eventos adversos aumentam a propensão ao desenvolvimento dessa condição.Nesse contexto, é possível notar que a depressão e seu crescimento significativo apontam para problemáticas mais amplas do mundo em que vivemos, para além das relações familiares privadas ou questões restritas ao âmbito individual.

As vivências depressivas que se manifestam individualmente, na verdade podem expressar condições sociais relativas à exclusão social e diversas vulnerabilidades. A vulnerabilidade social seria a diminuição das possibilidades de enfrentamento de situações de risco (ROMAGNOLI, 2015). Relações sociais frágeis ou isolamento social, acesso precário a políticas públicas de proteção, desemprego ou baixa renda, condições básicas de vida insuficientes, são alguns fatores que configuram a vulnerabilidade social. A escassa proteção social e estatal pode ser fator produtor de depressões, psicoses e outros transtornos, para além de estas serem condições relativas somente a predisposições individuais. Neste sentido, Sawaia(2014, p. 100) argumenta que "é o indivíduo que sofre, porém, esse sofrimento não tem a gênese nele, e sim em intersubjetividades delineadas socialmente".

De acordo com Romero (1994), a depressão está diretamente relacionada às possibilidades disponíveis ao indivíduo de sair ou lidar com eventos que podem significar a perda de sua base de sustentação. Neste sentido, a situação de vulnerabilidade social pode ser associada à depressão, uma vez que, pessoas excluídas têm

1. Dados pesquisados no site da OPAS - Organização Pan Americana de Saúde:https://www.paho.org/bra/index.php?option=com_content\&view=article\&id=5635:folha-informativa-depressao\&Itemid=1095 
Um estudo sobre exclusão social e depressão a partir do plantão psicológico Mikelly Neves Silva • Érico Douglas Vieira

menos possibilidades disponíveis de respostas. Em termos sociais mais amplos, essa perda da base de sustentação pode representar, por exemplo,uma situação de desemprego, vínculos familiares e sociais rompidos, uma sequência de fracassos pessoais, dentre outras situações. Embora estes fatores de risco ocorram com pessoas de todas as classes sociais, a situação de pobreza agrava a potencialidade de risco e a vulnerabilidade social.

O neoliberalismo, como ideário do capitalismo financeiro contemporâneo, pode gerar ou agravar vivências características da sintomatologia depressiva. Bauman (2007) discorre sobre o sentimento generalizado de insegurança, a fragilidade e transitoriedade dos laços humanos e a desresponsabilização do Estado com os mecanismos de proteção social presentes na contemporaneidade. Neste sentido, o indivíduo deve resolver de maneira individual os problemas produzidos socialmente. Tais características neoliberais configuram uma estruturação social que promove cada vez mais incertezas, inseguranças, privatização dos problemas e solidão, impotência e ansiedades existenciais (BAUMAN, 2007).

Portanto, as vivências depressivas podem representar um sintoma social que revela o significativo desamparo produzido a partir do descompromisso estatal e social com uma parcela da população que vive sua vida cotidiana com base na precariedade e na escassez. As ciências sociais e humanas são convocadas a contribuir para desnaturalizar a imensa desigualdade social brasileira, tornando visíveis as experiências concretas dos sujeitos excluídos.

\section{Método}

O presente estudo se insere no referencial epistemológico das pesquisas qualitativas em ciências sociais, que tem como foco 
Um estudo sobre exclusão social e depressão a partir do plantão psicológico Mikelly Neves Silva • Érico Douglas Vieira

a compreensão de casos particulares e não a formulação de leis generalizantes, buscando apreender os significados das experiências dos sujeitos a partir do contexto em que foram vividas (GOLDENBERG, 2015). Dentro do referencial qualitativo, a Teoria Fundamentada foi adotada nesse estudo. As diretrizes desta metodologia direcionam a coleta e a análise dos dados com vistas à construção de conceitos teóricos fundamentados nos próprios dados, em vez de se adotarem hipóteses preconcebidas (CHARMAZ, 2009).

O material da pesquisa foi coletado a partir dos atendimentos psicológicos do tipo Plantão Psicológico, realizados de segunda a sexta, de 10:00 às 12:00 horas, em uma instituição de apoio de uma cidade do interior de Goiás. Além do acolhimento, o plantão psicológico é um tipo de escuta que amplia a clínica psicológica por ser uma modalidade inserida em instituições ou nas comunidades.Caracteriza-se por uma escuta pontual e qualificada oferecida de maneira contínua, em locais e horários determinados e divulgados previamente. Os usuários chegam ao atendimento de forma espontânea, sem agendamento prévio, com dificuldades circunstanciais como demanda. O plantonista se coloca à espera da comunidade, oferecendo um suporte em momentos de crise. Busca acolher e lidar com a demanda trazida com base na experiência do próprio sujeito (MAHFOUD, 2012).

Este trabalho de investigação teve como objetivo buscar possíveis manifestações da desigualdade e da injustiça social brasileiras no espaço clínico dos plantões psicológicos. Mais especificamente, de que maneira a marginalização e a vivência da vulnerabilidade social podem ser produtoras de condições que fragilizam os sujeitos, como as vivências depressivas. Para a coleta de dados foram utilizados os diários de campo elaborados pela equipe de pesquisa/intervenção. Estes diários são registros do material que emerge 
Um estudo sobre exclusão social e depressão a partir do plantão psicológico Mikelly Neves Silva • Érico Douglas Vieira

no espaço das interações clínicas, com observações, sentimentos e elaborações do plantonista. Para cada atendimento clínico realizado foi produzido um diário de campo, gerando o material a ser analisado pelos pesquisadores. Para este artigo, foram delimitados e analisados os diários produzidos pelos membros da equipe de pesquisa e extensão no ano de 2019.

Os participantes do projeto não buscaram diagnosticar a depressão, mas identificar nos diários de campo vivências depressivas. Portanto, para fins dessa análise, dos 123 diários de campo que correspondem aos documentos produzidos semanalmente pela equipe de pesquisa entre os meses de janeiro e dezembro do ano de 2019, foram selecionados e codificados 40 diários, mediante a identificação de algum traço e/ou vivência depressiva.

A análise dos dados consistiu no processo de codificação de cada diário de campo. O primeiro passo foi a codificação inicial que consistiu em nomear frações dos dados de modo a resumir e representar analiticamente cada segmento dos diários de campo. Depois de gerados e sistematizados, os códigos iniciais orientaram o segundo passo, a codificação focalizada. Nesse procedimento os códigos iniciais mais frequentes e que geraram melhor compreensão analítica foram selecionados, refinados e agrupados, a fim de uma categorização adequada (CHARMAZ, 2009). A partir do agrupamento dos códigos com o mesmo teor temático, foram construídas categorias que representaram os resultados desta pesquisa. As categorias construídas foram: (1) Rupturas relacionais e maus encontros; (2)Exclusão social e desvinculação com o mundo e (3) Potências manifestadas no espaço clínico. Estas categorias serão apresentadas e discutidas a seguir. 
Um estudo sobre exclusão social e depressão a partir do plantão psicológico Mikelly Neves Silva • Érico Douglas Vieira

\section{Resultados e Discussão}

\section{Rupturas relacionais e maus encontros}

Essa categoria apresenta vivências depressivas associada a rupturas relacionais, desencontros e maus encontros interpessoais que enfraquecem, desvitalizam e geram uma sensação de desenraizamento e não pertencimento. Tratam-se de experiências relacionais que resultam em sofrimentos que fragilizam e que conduzem a um progressivo apagamento subjetivo. Nesse sentido, foram identificadas experiências de culpa, vazio, solidão e abandono, gerando uma sensação perene de desamparo. A desqualificação e o desprezo recebidos nos vínculos constituem uma sensação de escassez de experiências de valorização e de reconhecimento. Os maus encontros de sujeitos excluídos com pessoas de outras classes através das vozes de mandos e dos olhares de rebaixamento, podem aumentar a sensação de vulnerabilidade.

Os relatos de vivências intensas de perda de algo ou de alguém importante, além do sofrimento associado a reiteradas perdas foram narrativas que impactaram os plantonistas pela intensidade presente. Por exemplo, o relato de um usuário que foi internado em um hospital psiquiátrico após a perda trágica de sua esposa, demonstra que a intensidade da perda pode desintegrar a subjetividade. Ao vivenciar uma perda significativa ou reiteradas perdas, sentimentos acentuados de desânimo, abatimento e encolhimento se instalam, podendo significar uma perda da base de sustentação (ROMERO, 2004).

Nas escutas dos plantões psicológicos, foi possível perceber narrativas de vivências ligadas à depressão em conexão com a solidão ou perda de um vínculo. A falta de relações interpessoais e vínculos significativos geraram um sentimento de vazio e solidão 
Um estudo sobre exclusão social e depressão a partir do plantão psicológico Mikelly Neves Silva • Érico Douglas Vieira

que causaram nos sujeitos uma sensação de se sentirem menos importantes, de desqualificação pessoal. Muitos usuários se viam como sem valor diante de vivências de abandono, rejeição e exclusão, se sentiam insuficientes em suas relações, diversas vezes eram tratados como "apêndice inútil da sociedade" (SAWAIA, 2014, p.101).

As pessoas excluídas experimentam um sofrimento de natureza ético-político que as impede de se reconhecerem como partes importantes da sociedade (SAWAIA, 2014). Este sofrimento, por meio de mensagens de rebaixamento, ecoa subjetivamente nos sujeitos causando dor e inibição das iniciativas e interações sociais (COSTA, 2004). Wanderley (2014, p. 24), afirmaque, "no mundo das relações sociais a fragilização dos vínculos - família, vizinhança, comunidade, instituições - pode produzir rupturas que conduzem ao isolamento social e à solidão".

Os sofrimentos diante da ruptura de vínculos familiares foram bastante relatados. As dificuldades de inserção profissional e o uso problemático de álcool e outras drogas podem desestabilizar e romper as relações familiares. Conforme percebido nas narrativas, os membros familiares não suportaram os comportamentos instáveis e destrutivos do sujeito com problemas de dependência química, culminado na exclusão dele do grupo familiar. O uso abusivo de álcool e outras drogas foi tido como uma via para suportar sentimentos e vivências difíceis. Diversos usuários disseram fazer uso das substâncias para terem paz e coragem, ou para se livrarem de pensamentos perturbadores e até mesmo do frio e da fome. Pessoas de classes populares recorrerem a substâncias psicotrópicas como uma forma de escapismo de se verem sem futuro (SOUZA, 2017). No entanto, este recurso fragiliza as relações que poderiam dar suporte ao sujeito.

O desemprego também foi um fator que esteve correlacionado à retirada de apoio da família. Ou seja, quando a situação 
Um estudo sobre exclusão social e depressão a partir do plantão psicológico Mikelly Neves Silva • Érico Douglas Vieira

de trabalho é desfavorável, os sujeitos recebem menos suporte familiar. Este achado da presente pesquisa está em sintonia com o processo de desqualificação social descrito por Paugam (2014). $O$ autor argumenta que a desvalorização da pobreza enfraquece os laços sociais, na medida em que os excluídos sentem que precisam esconder a própria situação de inferioridade. Ou o próprio meio social e familiar tende a rejeitar um membro que está em situação precária. Ele afirma que "quanto mais precária for a situação no mercado de trabalho, maior é a possibilidade de o indivíduo não ter nenhuma relação com a família" (PAUGAM, 2014, p. 74).

Houve relatos de humilhações, desprezos e maus tratos vividos nas relações familiares. Estas vivências parecem ter desencadeado angústias de difícil manejo por parte do sujeito, levando o mesmo a atribuir um baixo valor a si mesmo. As situações em que foram humilhados por algum membro da família representaram maus encontros, com a consequente sensação de desqualificação e incapacidade. Foi possível perceber nos discursos reações que vão da revolta a uma desintegração da subjetividade, tendo como consequências uma dificuldade de organizar a própria vida e vivências depressivas de vazio e falta de sentido. Como no caso de uma usuária com diagnóstico de depressão que diz ter sido muito humilhada e rejeitada pela mãe. Ela conta que sempre se sentiu frágil, desprezada e desamparada, dizendo: "minha mãe nunca gostou de mim porque não sou bonita e tenho cabelo crespo". Souza (2017) aponta que uma singularidade brasileira é o abandono e o desprezo seculares dirigidos às classes populares que ainda perdura nos dias atuais. As pessoas das classes excluídas são percebidas como subgente, como menos humanas do que as classes incluídas. Como consequência deste processo, esta violência simbólica é reproduzida no meio familiar, sendo que os mais frágeis se tornam alvos das opressões.A falta de reconhecimento 
Um estudo sobre exclusão social e depressão a partir do plantão psicológico Mikelly Neves Silva • Érico Douglas Vieira

nas relações interpessoais foi narrada como um fator de enfraquecimento pessoal gerado pela falta de confirmação e valorização de si mesmo. Pode ser que todo o desprezo que a sociedade dirige para as classes populares circule nas relações entre os sujeitos (SOUZA, 2017).

Portanto, os relatos dos sujeitos demonstraram que a ruptura, os desencontros e maus encontros relacionais, assim como perdas significativas podem conduzir a um processo de desvitalização e fragilização, com progressivo apagamento subjetivo e vivências depressivas.

\section{Exclusão social e desvinculação com o mundo}

Nesta categoria são relatadas experiências que articulam as vivências depressivas com a experiência da exclusão social. O fechamento das possibilidades, a falta de perspectivas e de saídas parecem provocar uma significativa desvinculação com o mundo, suas atividades, demandas e relações. A sensação de encolhimento e retração, a perda da vitalidade e a sensação predominante de desvalor de si mesmo retiram os sujeitos do circuito das demandas e convites do mundo.A visão rebaixada ou depreciativa de si mesmo ocasionada pelas humilhações sociais vividas nos encontros com as classes incluídas podem produzir afetos e pensamentos ligados à vivência depressiva, como a falta de esperança, sensação de impotência e até mesmo uma dificuldade de sustentar o vínculo com o mundo percebida por ideações suicidas. Os sujeitos das camadas populares possuem condições materiais e simbólicas precárias para construírem suas subjetividades (BOCK, 2009).

A percepção da própria vida como uma sucessão de fracassos parece suscitar uma forte sensação de desvalor de si mesmo. Um usuário relatou um delírio que parecia representar a percepção 
Um estudo sobre exclusão social e depressão a partir do plantão psicológico Mikelly Neves Silva • Érico Douglas Vieira

negativa de tinha de si mesmo, dizendo se ver como o "satanás". Outro usuário relatou que se percebe como alguém insignificante, falou sobre suas ideações e reiteradas tentativas de suicídio e disse: "sinto que, caso morresse, não faria falta pra ninguém, só tomo decisões erradas e as coisas ruins só acontecem comigo". As experiências depressivas pareceram estar associadas com uma angústia e mal-estar difusos. Sintomas corporais e o sofrimento vivido como algo incomunicável para outro são exemplos desta angústia difusa. Um usuário descreveu sua depressão como "uma angústia que aparece do nada".

Um usuário mostrou a carteira de trabalho aos plantonistas, dizendo que teve uma vida cheia de empregos, antes de estar em situação de rua. Ele disse em determinado momento: "Eu nunca dormi na rua ou andei assim. Olha o meu estado! Estou muito triste e sem forças e fico pedindo para Deus me levar". Ele também disse: "Não me reconheço como pessoa, agora sou fraco". Muitos sujeitos percebem suas vidas como uma série de fracassos e se culpam por seus descaminhos. O olhar fica restrito somente aos seus desempenhos individuais. Parecem não terem consciência dos problemas de estrutura social que compõem suas vulnerabilidades. Ou seja, as condições materiais e simbólicas para a construção da subjetividade e para a inserção social estão muito mal distribuídas na sociedade. A desigualdade social no Brasil é camuflada pela disseminação de uma visão liberal de sociedade, em que o esforço individual é o único fator determinante de sucesso ou fracasso (SOUZA, 2015).

A vida como uma sucessão de fracassos pode colocar as relações consigo mesmo marcadas por vivências de culpa, hostilidade e autodestruição. Essa destrutividade dirigida a si mesmo normalmente estava relacionada ao uso problemático de drogas, além da permanência em relações amorosas tóxicas. Um usuário relata 
Um estudo sobre exclusão social e depressão a partir do plantão psicológico Mikelly Neves Silva • Érico Douglas Vieira

que chegou a romper o vínculo trabalhista como uma forma de se punir. Outra usuária buscou o plantão para tentar entender as próprias vivências autodestrutivas, referindo-se a episódios de autoagressão, tentativas de fazer com que o motorista do carro em que se encontrava perdesse o controle da direção. Romero (2004) pontua que dentre os sentimentos que configuram o quadro depressivo está a culpa, a autodesvalorização e autoagressão. A culpa exige um castigo que o próprio sujeito se empenha em aplicar-se, resultando em sofrimento, tormento e dilaceração.

O suicídio e as experiências de ideação suicida, foram aspectos que permearam a maioria das escutas consideradas como tendo alguma experiência depressiva. A vivência subjetiva de não querer existir ou de querer se isolar também emergiu no espaço clínico. Nesse sentido é válido dispor das contribuições de Sawaia (2014, p. 103), ao afirmar que "corpo é matéria biológica, emocional e social, tanto que sua morte não é só biológica, falência dos órgãos, mas social e ética. Morre-se de vergonha, o que significa morrer por decreto da comunidade". A morte social, gerada pela vivência de ser inútil para a sociedade, instala a morte pela falta de possibilidades de inserção social.

A percepção e o contato com algumas vivências intensas e por vezes ligadas a vivências depressivas provocaram angústia nos plantonistas. Destacam-se a falta de perspectiva e de inserção social do usuário, o acentuado sofrimento, as ideações suicidas e até o reconhecimento de maus tratos sofridos pelo usuário. Nesse sentido, verificou-se a ressonância das impotências dos usuários nas plantonistas, um risco que existe, especialmente, quando se trabalha com indivíduos vulneráveis socialmente (ROMAGNOLI, 2015). Por exemplo, uma plantonista em seu relato disse que a expressão do sofrimento de uma usuária, sintetizado em uma frase "hoje sinto frio, dor e tristeza", a fez pensar em algumas rela- 
Um estudo sobre exclusão social e depressão a partir do plantão psicológico Mikelly Neves Silva • Érico Douglas Vieira

ções sociais em que se sente da mesma maneira: triste e solitária. O trabalho clínico se mostrou desafiador, constituindo-se em um processo atravessado por incertezas e que requer paciência, respeito e cuidado. De acordo com Romagnoli (2006, p. 54), clinicar é "[...] sustentar a diferença, que sempre nos traz a alteridade e, consequentemente o social, usando exatamente nosso conhecimento como suporte. Suportar o constante vir a ser do encontro, devir-outro, em ato".

As experiências de falta de perspectivas e falta de saída se manifestaram relacionadas no âmbito das relações interpessoais e no campo do trabalho. No caso das relações, houve relatos de usuários que se sentiam presos em relações amorosas sem sentido ou até mesmo opressoras e violentas. Diziam que permaneciam por medo da solidão ou por se sentirem impotentes para buscar uma saída. A falta de reconhecimento e valorização no trabalho, a vulnerabilidade diante da situação de desemprego, a precariedade na condição financeira, foram experiências relacionadas a vivências depressivas e ideações suicidas. A situação de vulnerabilidade social, condição agravada pela pobreza, influencia e tende a diminuir a potencialidade da resposta a situações conflitantes e ou ameaçadoras (ROMAGNOLI, 2015).

Diversos tipos de opressões relacionadas com a classe social foram narrados no espaço clínico, tais como reiteradas violências físicas e psicológicas, humilhações, experiências de racismo e preconceito, sensação de abandono e desamparo, desemprego e vivências de não se ter o que comer ou onde dormir. Estas vivências produzem fragilidade, através de uma visão rebaixada de si mesmo, angústia, impotência, culpa, autodesvalorização e ideações suicidas. Revela-se oportuna a problematização se as pessoas excluídas possuem maior risco de viverem experiências depressivas. Ser tratado como sem valor, sofrer humilhação, passar reiterada- 
Um estudo sobre exclusão social e depressão a partir do plantão psicológico Mikelly Neves Silva • Érico Douglas Vieira

mente por violências simbólicas e físicas, afetam diretamente a constituição da subjetividade e, portanto, o modo de ser-no-mundo do indivíduo.

As opressões relativas às questões de raça, classe social e gênero foram percebidas. Em algumas narrativas, foi notado que se perceber como pertencente a um grupo discriminado ou com pouco poder gerou um sofrimento significativo. Por exemplo, um usuário relatou que tinha pensamentos suicidas por não conseguir um emprego por ser um homem negro e marginalizado, ainda que tivesse experiência profissional em diversas áreas. Já quanto ao recorte de gênero, constatou-se que ser mulher é percebido como algo que diminui a potência de ação. Por exemplo, uma usuária ao relatar ser dependente do marido refletiu que "a mulher é frágil, o homem é forte".

De modo geral, percebe-se que as vivências depressivas estão correlacionadas com experiências concretas como desemprego, rupturas de vínculos, humilhações, opressões, rebaixamento, dentre outras situações desestabilizadoras. Tais vivências diversas vezes excederam a capacidade que o indivíduo tinha de enfrentamento das adversidades, fecharam as possibilidades de saída e foram tidas como uma perda da base de sustentação e, consequente, perda da vitalidade.

\section{Potências manifestadas no espaço clínico}

Nesta última categoria foram agrupados os dados que demonstraram de que maneira as vivências depressivas se manifestaram nos plantões psicológicos. O espaço e a escuta clínica apareceram como uma importante fonte de amparo e como desencadeadores de potencialidades expressas em vivências de integração, proteção, suporte e enfretamento. Além disso, esta 
Um estudo sobre exclusão social e depressão a partir do plantão psicológico Mikelly Neves Silva • Érico Douglas Vieira

categoria aborda algumas experiências dos plantonistas, como a realização sentida em proporcionar uma escuta clínica pontual e democratizada, e a potência advinda da consolidação de uma conexão e identificação com os usuários.

O impacto das vivências depressivas influenciou na busca pelos plantões psicológicos, seja na procura de uma ajuda pontual, seja na busca de entender melhor estas vivências depressivas. Houve usuários que buscaram o plantão após diagnósticos de depressão e/ou outros diagnósticos de transtornos mentais recebidos na rede de atenção psicossocial do município. Houve busca pela escuta clínica para relatar e entender as próprias ideações suicidas, bem como para entender a deterioração da própria vida.

Para além do caráter de acolhimento, o plantão psicológico se mostrou como um espaço de esclarecimento, orientações e encaminhamentos. Ao ampliar a compreensão dos usuários sobre seus próprios transtornos e outras questões da subjetividade, os plantonistas procuraram explorar e entender a vivência depressiva com base na experiência do próprio sujeito. É importante que a prática clínica se dê no sentido de acolher e sustentar todas as existências em suas singularidades e que leve em consideração a influência social, cultural e histórica na construção das subjetividades (DUTRA, 2004). A ideia foi transmitir o conhecimento sobre as questões psicológicas de forma a ajudar os usuários a mapearem e nomearem os próprios sofrimentos, assim como identificar vivências depressivas. Os plantões psicológicos foram conduzidos de modo a ampliar o olhar sobre a demanda inicial e acolher o sofrimento do usuário (MAHFOUD, 2012). Um exemplo é o caso de um usuário que foi em busca de ajuda para o filho que estava com depressão, mas que teveas suas próprias angústias acolhidas, para além da demanda inicial. 
Um estudo sobre exclusão social e depressão a partir do plantão psicológico Mikelly Neves Silva • Érico Douglas Vieira

O espaço clínico representou um lugar de escuta e acolhimento, que possibilitou o resgate da humanidade dos usuários, na medida em que se buscou a validação das suas potências e capacidades. O autocuidado para além da medicalização também foi algo gestado nos encontros. O alívio e a liberdade de expressão sentidas ao conversar com alguém que o reconhece, parece suscitar sentimentos de esperanças e vislumbre de novas perspectivas, ressignificações e elaborações. O espaço clínico possibilitou também reflexões sobre diferentes temáticas como dificuldade em relacionamentos interpessoais, dependência química e as consequências adversas do abusivo de álcool e outras drogas. Se a humilhação reverbera na subjetividade do sujeito, o reconhecimento e a admiração também podem produzir efeitos potentes. Enquanto no primeiro caso, o efeito é de rebaixamento, o reconhecimento pode facilitar a produção de novas identidades, distintas daquelas ligadas ao imaginário social de inutilidade e marginalidade (DELFIN; ALMEIDA; IMBRIZI, 2017).

Os aspectos potentes que foram identificados e validados em sujeitos que sentiam o peso da estigmatização da sociedade foram elementos importantes.Alguns usuários apresentaram o desejo de melhorar a própria vida para conseguirem uma maior realização pessoal. Uma usuária disse já ter pensado em suicídio, mas que "agora pensa em viver". Notaram-se também algumas vivências ou fatores de integração que parecem ter sido formas de proteção, suporte e enfrentamento diante de vivências desestabilizadoras. Alguns fatores protetivos foram: a inserção em alguma religião, os vínculos interpessoais, incluindo os vínculos construídos com os plantonistas, os relacionamentos conjugais, a inserção no mundo do trabalho, dentre outros. Além disso, alguns usuários relataram que percebem a medicalização como algo integrador. Tanto o trabalho voluntário quanto a con- 
Um estudo sobre exclusão social e depressão a partir do plantão psicológico Mikelly Neves Silva • Érico Douglas Vieira

vivência na casa de apoio foram citados pelos usuários como instrumentos de integração e, em alguns casos, como meio de enfrentamento dos transtornos mentais. Nesse sentido, Paulon e Romagnoli (2018), pontuam que são a partir das relações ou os encontros produtores de vida que se originam as potencialidades de um corpo.

Alguns plantonistas revelaram que a escuta clínica pontual e democratizada produziu sentimentos de realização pessoal. Este sentimento se manifestou diante da consolidação de uma conexão e uma identificação com o usuário. A relação clínica se mostrou provocadora de reflexões em ambos os envolvidos e possibilitou que o plantonista ampliasse seu olhar sobre o usuário, percebendo potencialidades antes não identificadas.

Por fim, foi possível notar que o plantão psicológico, mesmo sendo uma escuta pontual, se concretizou como um espaço de acolhimento, orientações, esclarecimentos e encaminhamentos. Este espaço se constituiu como suporte, resgate da humanidade dos usuários e lugar de aparição das potencialidades. A potência existente em sujeitos excluídos e a importância de validar e reconhecer suas capacidades, habilidades e vivências integradoras foram aspectos muito significativos. Apesar dos desafios encontrados pelos plantonistas, a realização em fazer uma clínica democratizada foi ressaltada como algo que proporcionou muito aprendizado.

\section{Considerações Finais}

Este estudo partiu da hipótese de que sintomas psicopatológicos que se manifestam no sujeito, na verdade podem ser expressões de questões sociais mais amplas, relativas à soma de diversas 
Um estudo sobre exclusão social e depressão a partir do plantão psicológico Mikelly Neves Silva • Érico Douglas Vieira

vulnerabilidades. Mais especificamente, buscou-se uma análise da exclusão social como condição produtora de vivências depressivas.

A partir da análise do material coletado em atendimentos na modalidade do plantão psicológico, foi possível verificar a correlação entre vivências depressivas e rupturas relacionais e maus encontros.A dimensão subjetiva da desigualdade social por meio de expressões que revelaram a construção das subjetividades marcada por rebaixamentos, humilhações, condições materiais e simbólicas precárias foi fortemente notada. Estas situações desestabilizadoras geraram afetos ligados a desvinculação com o mundo, à falta de perspectivas e de saídas e uma perda de vitalidade. O plantão psicológico foi uma importante fonte de amparo e acoIhimento, além de ser um espaço de revelação de potências em sujeitos marcados por situações sociais que os fragilizam.

A pesquisa revelou ser necessário construir ações singulares e relações clínicas que favoreçam encontros horizontalizados, com a valorização e admiração como contraponto diante de humilhações reiteradas. A escuta do sofrimento de sujeitos de classes populares convoca o clínico para pensar as questões que se manifestam no sujeito individual como expressões de questões do seu contexto social. A fragilidade dos laços familiares e sociais, a dependência química, as questões de saúde mental requerem pesquisas que contextualizem estas manifestações inseridas num contexto social de vulnerabilidades decorrentes do pertencimento de uma classe excluída.Espera-se que essa pesquisa fomente novas possibilidades de intervenções, estudos e políticas públicas que possam dar poder de palavra aos sujeitos de classes populares e que evidenciem a influência das condições sociais na produção de subjetividades. 
Um estudo sobre exclusão social e depressão a partir do plantão psicológico Mikelly Neves Silva • Érico Douglas Vieira

\section{Referências}

BAUMAN, Zigmunt. Tempos líquidos. Rio de JANeIRO: Zahar, 2007.

BOCK, Ana Mercês Bahia. Dimensão Subjetiva da Desigualdade Social: um estudo na cidade de São Paulo. Pontifícia Universidade Católica de SÃo Paulo, 2009. Documento disPonívelem: hTtP://WWW.ABRAPSO.org.BR/ SITEPRINCIPAL/IMAGES/ANAIS_XVENABRAPSO.

CHARMAZ, Kathy. A CONSTRUÇÃo DA TEORIA FUNDAMENTAdA: GUIA PRÁtico para análise qualitativa. Porto Alegre: Artmed, 2009.

COSTA, Fernando Braga. Homens Invisíveis: relatos de uma humilhação SOCIAL. SÃo PAULO: GLobo, 2004

DElFiN, Lucas; AlMEIDA, Lara Aparecida Machado de; IMBRIZI, Jaquelina Maria. A rua como palco: arte e (in)visibilidade social. Psicologia \&

Sociedade, Belo Horizonte, v. 29, N. 1, P. 1-10, 2017.

DUTRA, ElZA. Considerações SOBRe AS SIGNIFICAÇõES DA PSICOLOGIA CLínICA NA contemporaneidade. Estudos de Psicologia, v. 9, N. 2, P. 381-387, 2004.

GOldenBerg, Mirian. A arte de Pesquisar: Como fazer Pesquisa qualitATIVA EM CIÊNCIAS SOCIAIS.14. ed. RIO DE JANEIRO: RECORD, 2015.

MAhfoud, Miguel. Plantão Psicológico: Novos Horizontes. São PauLO: Companhia Ilimitada, 2012.

PAUGAM, Serge. O enfraquecimento e a Ruptura dos vínculos socials UMA DIMENSÃO ESSENCIAL DO PROCESSO DE DESQUALIFICAÇÃO SOCIAL. IN: SAWAIA, Bader (ORG.). As aRtimanhas dA EXCLUSÃo: ANÁlise PSICOSSOCIAL E ÉtICA DA desigualdade social. Petrópolis: Vozes, 2014, P. 69-88.

PAUlon, Simone Mainieri; ROMAGNOLI, Roberta Carvalho. Quando a vulnerabilidade Se faz potência. Interação em Psicologia, v. 22, N. 3, P. 178-187, 2018. 
Um estudo sobre exclusão social e depressão a partir do plantão psicológico Mikelly Neves Silva • Érico Douglas Vieira

ROMagnoli, Roberta Carvalho. Algumas reflexões acerca da Clínica Social. Revista da UFF, v. 18, N. 2, P. 47-56, 2006.

ROMAGNOli, Roberta Carvalho. Problematizando as noções de vulnerabilidade e risco social no cotidiano do SUAS. Psicologia em Estudo, v. 20 N. 3, P. 449-459, 2015.

ROMERO, EMílIO. DetrÁs dE UM VIDRO ESCURO: AS VIVÊNCIAS DOMINANTES NA DEPRESSÃO. IN: ROMERO, EMÍlIO. O INQUILINO dO IMAGINÁRIO: FORMAS MALOgradas de existência. São José dos Campos: Della Bídia, 2004. P. 184-206. SAFATLE, Vladimir. Bem-Vindo ao estado suicidário. São PaUlo: Edições N-1, 2020.

SAWAiA, Bader. As artimanhas da exclusão: anÁlise pSicossocial e ética da desigualdade social. 14.ed. Petrópolis: Vozes, 2014.

SAWAIA, BADER. O SOFRIMENTO ÉTICO-POLÍTICO COMO CATEGORIA DE ANÁLISE DA Dialética eXClusão/InClusÃo. IN: SAWAiA, Bader (org.). As artimanhas da eXclusão: anÁlise psicossocial e Ética da desigualdade social. Petrópolis: Vozes, 2014, P. 99-119.

SOUZA, Jessé. A tolice da INTELIGÊNCIA BRAsileira: ou como o PAís SE deiXA manipular Pela elite. São Paulo: Leya, 2015.

SOUZA, Jessé. A elite do atraso: da escravidão À Lava Jato. Rı de JanelRO: LeYA, 2017.

WANDERLEY, MariangelaBelfiore. Refletindo sobre a noção de EXClusão. IN: SAWAiA, Bader (ORG.). As ARTIMANHAS dA eXCLUSÃo: anÁlise PSICOSSOCial e ética da desigualdade social. Petrópolis: Vozes, 2014, P. 17-27. 